\title{
The effect of angle between the oblique lines on the decrement of the Müller-Lyer illusion with extended practice
}

\author{
ROBERT E. DEWAR \\ UNIVERSITY OF CALGARY
}

Early work on the Muller-Lyer illusion had indicated that it disappears with extended practice. The present experiment failed to confirm this finding. The magnitude of the illusion decreased for approximately 500 trials, but showed no further change over an additional 500 trials. The rate of the practice decrement was inversely related to the size of the angle formed by the oblique lines of the figure.

In judging the Muiller-Lyer illusion figure, most Ss make an initial error of 10 percent or greater. If the figure is judged a number of times, however, the magnitude of this error decreases. The first investigator to observe this effect was Heymans (1896), although he did not make a systematic investigation of the phenomenon. Judd (1902) had Ss judge the figure from 20 to 200 times per day until the illusion disappeared. This required between 600 and 980 trials.

Lewis (1908) found similar results upon testing Ss over a period of up to 20 days. For some of his $\mathrm{Ss}$ the illusion disappeared completely, while others showed approximately a 50 percent decrement. Seashore, Carter, Farnum, and Sies (1908) also studied the decrement of the illusion with extended practice. Although there were large individual differences, they found a general decrement in the magnitude of the illusion when $\mathrm{Ss}$ were administered 20 trials per day for periods varying from 12 to 35 days. However, one $S$ showed no practice decrement whatever.

More recently, Köhler and Fishback (1950a, b) have reported that the illusion decreases to zero in somewhat fewer trials than was reported by the early investigators. With five of the $\mathrm{Ss}$, for example, the illusion disappeared after 20,24, 128, 144, and 200 trials.

Judd (1902) and Seashore et al (1908) found some degree of negative illusion after extended practice. Köhler and Fishback (1950a) reported up to 14 percent negative illusion in three of their Ss with whom practice was continued after the illusion had disappeared. They interpret this as support for the satiation interpretation of the practice decrement of the illusion.

Köhler and Fishback (1950b) found that a 24-h rest between series of trials resulted in a decrease in the illusion. This is not consistent with the findings of Mountjoy (1962), who reports no change in the magnitude of the illusion following a 24-h rest period and a significant increase in the illusion after longer rest periods.
Few investigations of the practice decrement of this illusion have used more than 100 trials. Dewar (1967) found that the decrement over a series of 100 trials was inversely related to the angle between the oblique lines of the figure. However, none of his groups showed a decrement of more than 50 percent with this amount of practice. This differential effect of angle between the obliques was attributed to S's paying greater attention to the horizontal line in the small-angled figures which are initially more difficult to judge and require greater effort on the part of $\mathrm{S}$ to overcome the distracting influence of the oblique lines. If degree of attention to the horizontal line does determine the rate of the practice decrement, it might be expected that the lllusion produced by a small-angled figure would drop below that produced by a large-angled figure, and possibly disappear in fewer trials with extended practice.

The purpose of the present study was to investigate the decrement of the Muiller-Lyer lllusion over a series of 1000 trials and to relate this decrement to the angle between the oblique lines.

\section{Apparatus and Procedure}

The apparatus consisted of a rectangular wooden panel $48 \mathrm{in}$. wide and $26 \mathrm{in}$. high. A piece of white stagblank, which served as a homogeneous background, was attached to the front of the panel. The stimulus (the Muiller-Lyer figure) was attached to the center of the panel and held firmly in place. The stimulus figure was constructed out of 10-ply stagblank and painted flat black. The horizontal portion of the figure was $20 \mathrm{~cm}$ in length (measured from the junctions of the horizontal line and the oblique lines). The lines of the figure were $4 \mathrm{~mm}$ in width. The movable center arrowhead of the figure was attached to a string that came through two small holes in the panel. The holes and string in front of the panel were hidden from S's view by the horizontal portion of the stimulus figure. The string was moved by a pulley driven by a reversible, variable speed, electric motor fixed to the back of the panel. The motor could be operated either by $\mathrm{E}$ or by a remote control key on the table in front of S. A pointer was fixed to the string behind the panel so that it moved along a scale on the back of the panel. The position of the center arrowhead could be measured to the nearest millimeter. When S's key was depressed, the center 
arrowhead moved at a speed of $1.4 \mathrm{~cm}$ per sec. The apparatus was set on a table 60 in. from S's head. A chin rest attached to the end of the table served to hold the head stationary and at eye level with the stimulus. After $S$ was seated, he was instructed to adjust the center arrowhead so that the two horizontal segments of the figure appeared to be equal in length. At the beginning of each trial, the adjustable center arrowhead was set by $E$ obviously too far to the right or to the left of the center position. These pretrial settings were made according to a predetermined random schedule.

The Ss assigned to the two experimental groups at random judged the figure 100 times per day for 10 days. Experimental sessions were at the same time each day on consecutive days except for the week-end, a two-day interval between Sessions 5 and 6. The oblique lines which formed the arrowheads of the flgure were $3 \mathrm{~cm}$ in length, but formed a different angle for the two groups. One group of 17 Ss judged a figure with a $60^{\circ}$ angle between the obliques, while the other group of $17 \mathrm{Ss}$ judged a figure with a $120^{\circ}$ angle. All Ss were paid $\$ 1.25$ per session.

\section{Sabjects}

The 34 Ss who took part in the experiment were undergraduate students and clerical personnel at the University of Calgary. Their mean age was 22.2 years.

\section{RESULTS}

Each S's trials were divided into blocks of 10 for the purpose of analysis. The analysis of variance indicated a significant decrement due to practice $(F=7.91$, df $=99, p<.001$ ) and a trials by angle inter- action $(F=1.76, \mathrm{df}=99, \mathrm{p}<.01)$. The magnitude of the illusion was much greater for the $60^{\circ}$ figure during early trials, but decreased rapidly within the first experimental session and fell below that of the $120^{\circ}$ figure at most points during the last five sessions (see Fig. 1).

The data were analyzed separately for each experimental session to determine whether the practice decrement occurred within sessions. These 10 analyses of variance indicated neither a significant practice decrement nor a trials by angle interaction beyond the flrst session (both were significant for the first session).

There was a regular decrement from session to session up to Session 5 for both figures. Beyond this point, the daily average shows no systematic trend.

\section{DISCUSSION}

The present results indicate a trials by angle interaction, but, although the small-angled figure does produce slightly less illusion in later trials (Sessions 5, 6, and 7 especially), there is no difference due to angle between the obliques after the first session. The magnitude of the illusion produced by both figures continued to decrease slightly up to Session 5. Any further training seems to be of little influence in reducing the fllusion.

The influence of a day's rest between sessions, which were administered at the same time each day, can be seen by comparing the last block of trials on any day with the first block on the next day. In the case of the $60^{\circ}$ figure there was a slight increase in the illusion over seven of the eight intervals (excluding the week end). This was essentially reversed

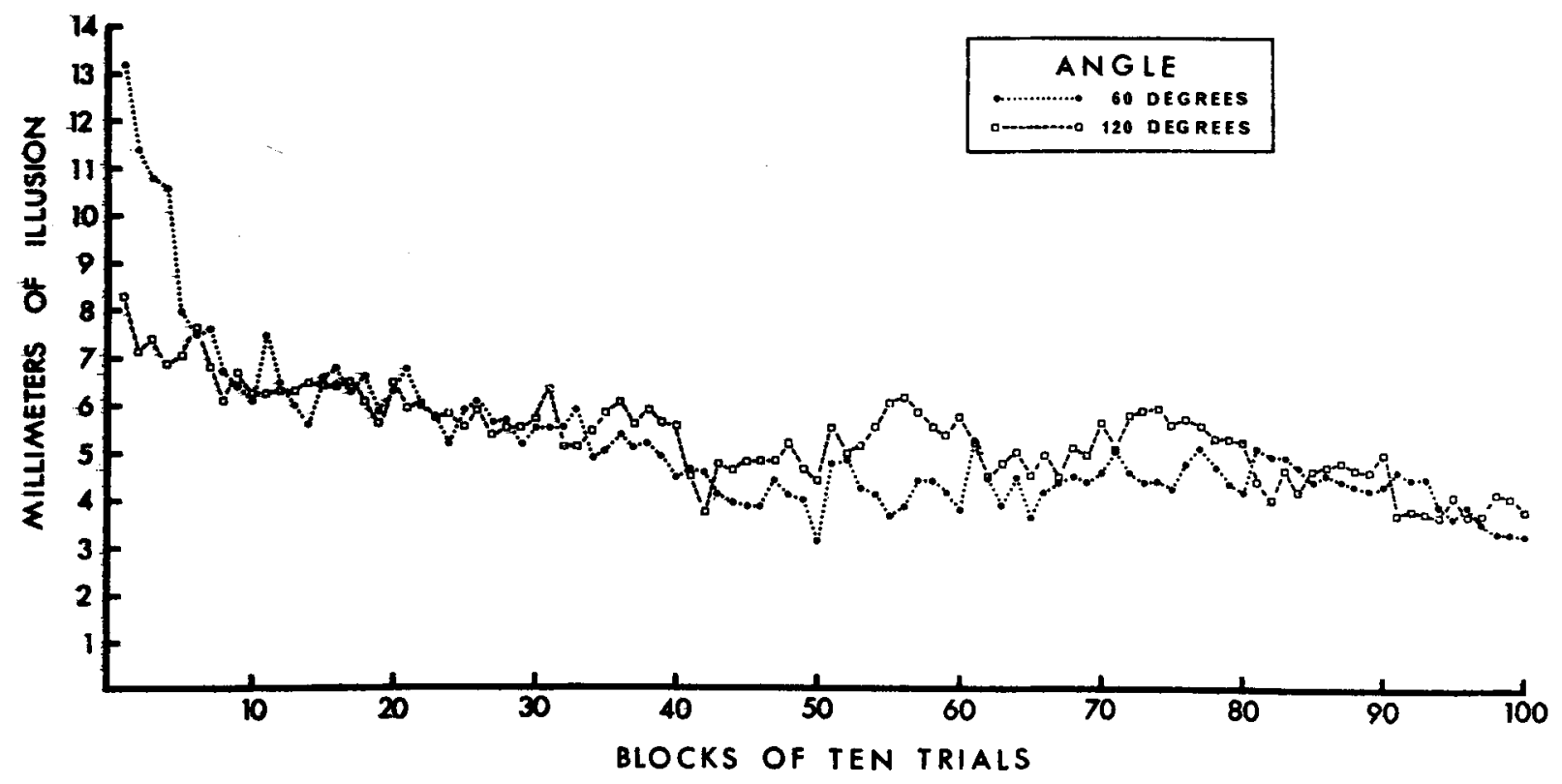

Fig. 1. Millimeters of illusion as a function of practice. 
for the $120^{\circ}$ figure, with a decrease in the fllusion over seven of the elght intervals. A mean increase of $4.8 \mathrm{~mm}$ of illusion was found for four Ss who were retested eight to 10 months after the experiment with the $60^{\circ}$ figure. Three Ss from the $120^{\circ}$ group showed a mean increase of $3.7 \mathrm{~mm}$ over this period. Seashore et al (1908) reported a return of the illusion to its initial magnitude in two Ss who were tested two years after their experiment.

The fact that the illusion did not completely disappear is contrary to the findings of Judd (1902) and Lewis (1908). They used very few Ss in their experiments, and not all were naive regarding the purpose of the experiment and expected results. Observation of individual $S s$ in the present experiment showed that some did have a negative illusion on some blocks of trials. The illusion disappeared and became somewhat negative for three of the Ss in the $60^{\circ}$ group. In the $120^{\circ}$ group, only one S had a systematic negative illusion. Several others had negative illusions on some blocks of trials, but did not show a systematic decrement to zero with no further change in the magnitude of the illusion. It would be expected that Ss who approached zero illusion would have negative readings on some trials. With the exception of four Ss, it cannot be said that the illusion disappeared within 1000 trials.

\section{SUMMARY}

Extended practice (1000 trials) in judging the Müller-
Lyer figure resulted in a marked decrement in the magnitude of the illusion. However, the illusion did not disappear as earlier investigators had reported. The magnitude of the illusion produced by a figure with a $60^{\circ}$ angle between the oblique lines was initially greater than that produced by a $120^{\circ}$ figure, but this difference disappeared after approximately 50 trials.

\section{References}

Dewar, R. E, Stimulus determinants of the practice decrement of the Müller-Lyer illusion. Canad. J. Psychol., 1967, in press.

Heymans, G. Quantitative Untersuchungen uber das "optische Paradoxon." Z. Psychol., 1896, 9, 221-255.

Judd, C. H. Practice and its effects on the perception of illusions. Psychol. Rev., 1902, 9, 27-39.

Köhler, W., \& Fishback, Julia. The destruction of the Müller-Lyer illusion in repeated trials: I. An examination of two theories. J. exp. Psychol., 1950a, 40, 267-281.

Kôhler, W., \& Fishback, Julia. The destruction of the Müller-Lyer illusion in repeated trials: II. Satiation patterns and memory traces. J. exp. Psychol., 1950b, 40, 398-410.

Lewis, E. O. The effect of practice on the perception of the MuillerLyer illusion. Brit. J. Psychol., 1908, 2, 294-306.

Mountjoy, P. T. Spontaneous recovery of the Müller-Lyer illusion. J. Scient. Lab., Denison U., 1962, 45, 207-214.

Seashore, C. E., Carter, E. A., Farnum, Eva C., \& Sies, R. W. The effect of practice on normal illusions. Psychol. Rev. Monogr. Suppl., 1908, 9, 103-148.

\section{Note}

1. This research was supported by Defense Research Board of Canada, Grant No. 9425-18.

(Accepted for publication May 28, 1967.) 